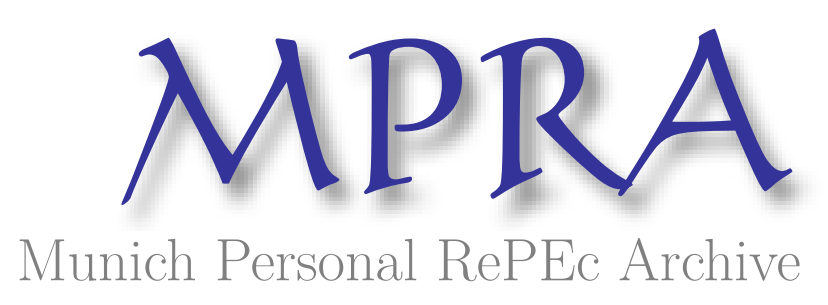

\title{
The Effect of Casual Teaching on Student Satisfaction: Evidence from the UK
}

Williams, Rhys

29 November 2020

Online at https://mpra.ub.uni-muenchen.de/106024/

MPRA Paper No. 106024, posted 11 Feb 2021 09:32 UTC 


\title{
The Effect of Casual Teaching on Student Satisfaction: Evidence from the UK
}

\author{
Rhys J. Williams ${ }^{\dagger}$ \\ London Economics, UK
}

$29^{\text {th }}$ November, 2020

\begin{abstract}
Using data on student satisfaction and teaching time in the UK, this paper examines how the proportion of teaching conducted by casual staff affected student satisfaction ratings for the 2014-15 academic year. It is found that an increased proportion of teaching delivered by casual staff leads to lower student satisfaction, even when controlling for university and faculty fixed effects. This may be a result of the features of casual contracts or might reflect the characteristics of individuals taking up such contracts. Regardless, it suggests that there is a trade-off between increasing casualisation and student satisfaction which could have implications for future student demand. As a result, policymakers should consider the long-term implications before offloading teaching to casual staff.
\end{abstract}

JEL classifications: I20, I23, C21, J41

Keywords: Casual Contracts, UK Higher Education, Student Satisfaction, Educational Economics

\section{Introduction}

As a result of funding constraints, an increasing proportion of teaching load is being placed on staff employed on casual contracts, rather than those on permanent contracts. In fact, in 2015/16, an average of $27 \%$ of undergraduate teaching was being delivered by hourly-paid staff, according to Freedom of Information responses from universities (UCU 2018). This compares with an average proportion of teaching conducted by casual staff of $13 \%$ in $2014 / 15 .{ }^{1}$ Whilst the samples used to calculate these two statistics are not identical - making exact comparison problematic - it shows that a significant proportion of undergraduate teaching is being conducted by casual staff, and this figure may be increasing over time.

If students have a preference for being taught by permanent teaching staff, then the increase in the use of casual contracts will likely lead to a reduction in student satisfaction. Moreover, this has the potential to affect future demand, through the impact of student satisfaction ratings and their influence in university league table rankings, for those institutions which place a larger proportion of teaching onto casual staff. On the other hand, if there is no empirical evidence to support the proposition of a student preference for being taught by permanent staff, then this would justify greater use of casual teaching, which may help resolve funding issues at universities, notwithstanding the effects of casual contracts on employees themselves.

Student satisfaction may be affected by the proportion of teaching conducted by casual staff for a number of reasons, either as a direct effect of the type of contract or indirectly

\footnotetext{
${ }^{\dagger}$ Correspondence to: Rhys J. Williams, London Economics, Somerset House, New Wing, Strand, London, WC2R 1LA, UK. Email: rhysjwilliams@cantab.net.

${ }^{1}$ See Section 4 for more details.
} 
via the individual characteristics of those employed on such contracts, or a combination of the two factors.

For instance, a casual teaching contract may pay staff by the hour for delivering teaching and, therefore, may not include dedicated hours for offering out-of-class contact time, preparing teaching material or marking assignment work, thereby leading to lower student satisfaction. Poorer remuneration may also mean that casual teaching staff have to take on a greater number of jobs, limiting their available time for student interaction. In addition, casual staff may be unable to influence the study curriculum and method of examination, potentially resulting in them teaching material they are less familiar with and which may not be suitable for the students in the class. On the other hand, staff employed on a casual contract may make a greater effort to deliver high-quality teaching if there is a prospect of them gaining more permanent employment. In this case, we might expect student satisfaction to increase when the proportion of casual staff increases. These would be cases where a feature of the contract affects student satisfaction.

It might also be the case that less experienced, younger or lower quality staff, unable to secure tenure, are more likely to accept casual contracts. Individuals with less experience and training in delivering teaching material are likely to have less satisfied students. On the other hand, younger individuals and those who were more recently taught themselves might have fresh insights into the teaching experience, which could lead to higher student satisfaction. This demonstrates the indirect link between the type of individual employed on casual contracts and student satisfaction.

These factors show that staff casualisation is likely to affect student satisfaction but it is not clear whether the overall effect will be positive or negative (or insignificant). In this paper, we seek to resolve this question by studying the relationship between the proportion of teaching delivered by staff on casual contracts and students' reported satisfaction with their time at university in the UK. We are the first to utilise data on student satisfaction combined with data on the proportion of teaching conducted by staff on permanent, fixed or casual contracts to explore the effect on student satisfaction of the amount of teaching conducted by casual staff in UK Higher Education Institutions (HEIs). The analysis is conducted at the university-subject level and focuses on the 2014-15 academic year. We therefore contribute to both the student satisfaction and the staff casualisation literature by addressing an empirical question which was previously unanswered. Moreover, our analysis also contributes to the broader contract literature, demonstrating potential indirect effects of casual contracts on performance outcomes.

We find that an increase in the proportion of teaching by casual staff results in a decline in student satisfaction: one percentage point increase in the proportion of teaching by casual staff results in a 0.23 percentage point reduction in the probability that a student will be very satisfied with their time at university. Instead, the higher proportion of teaching by casual staff means students are more likely to respond that they were only 'fairly satisfied' (increase of $0.12 \mathrm{pp}$ ), 'not very satisfied' (increase of $0.09 \mathrm{pp}$ ) and 'not at all satisfied' (increase of $0.02 \mathrm{pp}$ ). In itself, such an impact may seem small. However, the impact quickly compounds and, given the degree to which student satisfaction scores are clustered, and their overall impact on third-party rankings, these effects can have a substantial impact on university ranking tables (Gibbons et al. 2015). These findings would suggest policymakers at HEIs have a direct incentive to consider their employment practices in order to boost student satisfaction. In turn, this could lead to positive effects on future student demand through the impact of student satisfaction on university ranking 
tables.

This paper proceeds with a review of the previous literature on student satisfaction and the effects of staff casualisation in Section 2. Section 3 outlines the nature of our data whilst Section 4 presents descriptive statistics and other specific information about our dataset. In Section 5, we outline our methodology and estimation approach and Section 6 presents and discusses our results and potential explanations. Finally, Section 7 concludes and some areas for further research are provided.

\section{Previous Literature}

The existing literature can be separated into two strands focusing on student satisfaction or focusing on casual contracts. In the US, there is also a well-developed literature focusing on the use of adjunct professors, which, whilst based in a different institutional setting, has similarities to the casualisation literature (see, for instance, Figlio et al. 2015). To the best of our knowledge, we are the first to explore the relationship between student satisfaction and the use of casual contracts in an empirical setting. This may be as a result of a previous lack of data with which to adequately explore this question.

The existing casual contract literature highlights the role of labour market dualisation, with an expanding set of outsiders - those on precarious contracts - and a shrinking core of insiders, on permanent contracts (Afonso 2014). The reason such a situation arises, in this framework, is due to the large expansion in the number of $\mathrm{PhD}$ graduates without a similar increase in the number of permanent positions. With a large set of outsiders seeking to become insiders, there is an available supply of individuals willing to work on precarious terms due to the allure of relatively stable contracts later on in their career.

Whilst casual teaching can be seen as a convenient contractual arrangement for some staff members, it has primarily been used as an effective cost-reduction tool for financiallyconstrained universities (Junor 2004).

Evidence suggests that casual teaching staff are burdened with heavy teaching workloads, other employment and lack of time (Klopper \& Power 2014). Further evidence points to casual staff facing increased stress and anxiety as a result of the precarious and uncertain nature of their employment (Gill 2014, Lopes \& Dewan 2014, Allmer 2018, Loveday 2018). These factors may directly affect student satisfaction and could explain the link between casual teaching and student satisfaction.

In the student satisfaction literature, there is evidence to suggest that student satisfaction is affected by factors such as the number of staff at an institution and that this effect may propagate through university league tables. For instance, Lenton (2015) investigates the determinants of the National Student Survey (NSS), an alternative data source of student satisfaction, finding that the student-staff ratio and student employability are strong influencers of student satisfaction. Likewise, frequent staff-student interactions also lead to higher levels of student satisfaction (Richardson \& Radloff 2014).

Gibbons et al. (2015) show that NSS scores have a significant, albeit relatively small, effect on applications of home students at the university-subject level. This effect is propagated through the influence of the NSS on third-party university league tables. Similarly, Chevalier \& Jia (2016) find that a one standard deviation improvement in 
an institution's subject ranking score increases applications by around $4.3 \%$, although it should be noted that this paper focuses on subjects at an aggregated level. Further research corroborates that student satisfaction affects future demand (Soo \& Elliott 2010, Broecke 2015) and that this may be particularly important for international students (Chevalier \& Jia 2016, Horstschräer 2012).

\section{Data}

Two proprietary datasets are used to explore the relationship between student satisfation and staff casualisation: (1) survey results of UK university teaching staff, capturing the proportion of teaching by staff employed on a casual contract; and (2) survey results of undergraduate students across the UK, reporting their satisfaction with the university experience. Both datasets are available at university-subject level for the academic year 2014-15.

Whilst the Higher Education Statistics Agency (HESA) publish information on atypical academic staff, which has a similar definition to the definition of casual staff used in this paper, only information on the total number of atypical staff by university and cost centre is publicly available and there are many caveats associated with this data. ${ }^{2}$ For instance, atypical staff who are employed by an agency, self-employed, employed on an honorary contract or employed by a company consolidated in the higher education provider's accounts need not be included in HESA returns. Furthermore, HESA guidance states that atypical contracts are for less than four consecutive weeks or for one-off/shortterm tasks which thus excludes casual staff employed on a precarious contract for a longer period of time. Finally, it is likely that HEIs have differing definitions of atypical academic staff and, as a result, the data would not be comparable across institutions.

This motivates the use of the Union and College Union (UCU) survey, despite inevitable imperfections in the use of survey data. Furthermore, the survey allows the studying of the effect of the proportion of teaching conducted by casual staff, rather than the number of casual staff. It is expected that student satisfaction is likely to be more directly affected by the quantity of teaching performed by casual staff rather than the absolute number of casual teaching staff (who may only give a few hours of total teaching each).

In the UCU dataset, any survey responses from respondents who were not involved in teaching, provided more than one response or were at a further or alternative education provider were excluded. This leaves 1,521 university-subject observations with information on respondents' estimates of the average proportion of timetabled teaching time relating to undergraduate courses per week delivered by staff on open-ended/permanent contracts, fixed-term contracts or casual contracts. A casual contract is defined as a situation where an individual is employed on an 'as and when' basis, which may or may not be renewed. This includes zero hours, variable hours, sessional and termly contracts. A contract which lasts for one or two years is defined in the survey as being fixed.

This proportion of teaching time delivered by casual staff, given as a value between 0 and $100 \%$, was used as the key measure of staff casualisation in this analysis. Note that the proportion of teaching by permanent, fixed-term and casual staff jointly sum to $100 \%$.

\footnotetext{
${ }^{2}$ Also note that there is no requirement for HEIs to provide data on non-academic atypical staff.
} 
On average, there were 5.0 responses per university-subject pair, with a median of 3.0 responses. When considering the number of responses which contributed to each universitysubject observation, there is a clear trade-off between reliability and total number of observations. To elaborate, if the proportion of casual teaching in a given subject (at a given university) is determined by only a few respondents, then it is possible that the average of these responses is unreliable, as different staff members may have different knowledge of their department's employment practices and/or may be basing their response on their own personal experiences or those of close colleagues. Therefore, it is preferable for each university-subject observation to be based on as many responses as possible, to ensure that the average response accurately reflects the employment situation in that department. However, restricting university-subject observations to be based on a greater number of underlying responses reduces the number of observations which can be used for analysis. To alleviate such concerns and to balance the trade-off, any universitysubject observation based on fewer than five responses in the UCU survey is removed. Obviously, this reduces the number of university-subject observations which can be used for estimation so, as a robustness check, the analysis is replicated for observations based on three or more responses.

The second dataset comes from the 2014-15 Student Academic Experience Survey (SAES), a survey of full-time undergraduate students studying across the UK. This survey was run by YouthSight and jointly commissioned by the Higher Education Policy Institute and AdvanceHE. All UCAS starters are invited to join the panel which comprises around 1 in 20 current UK undergraduates (SAES et al. 2015). The survey investigated student satisfaction and the key variable of interest is the extent to which the student is satisfied with the overall quality of their course, denoted on a four-point Likert scale ranging from 'not at all satisfied' to 'very satisfied'.

Data on Russell Group membership, academic staff numbers and student numbers is obtained from HESA. ${ }^{3}$ A dummy variable is created if the university is based in London, as it is found that London is the only region of university location which has a statistically significant (negative) impact on student satisfaction rating. All variables are presented in Table 1. Staff numbers are provided at the university-subject level using 'HESA cost centres' rather than JACS1 subject, so we align each cost centre to the appropriate subject area. It is not possible to do this matching for 'combined' subjects, which we do not drop but retain with missing values for this variable.

\section{Descriptive Statistics}

Table 1 presents key descriptive statistics related to the dependent variables of interest in the sample. The dataset contains 8,767 university-subject observations. Within this sample, there were 120 different universities and 17 different subject areas at the one digit code level of the joint academic coding system (JACS) (see Annex for a full list of universities included in the sample; subject-areas are presented in Table 2).

The sample mean student satisfaction is 3.16, indicating that the average student was 'fairly satisfied' with their university experience. $2 \%$ of sampled students were 'not at all satisfied', 10\% were 'not very satisfied', 59\% were 'fairly satisfied' and $29 \%$ were

\footnotetext{
${ }^{3}$ Total student numbers are used, including both undergraduate and postgraduate. The results are insensitive to replacing this variable with undergraduate student numbers.
} 
'very satisfied'. Therefore, student satisfaction does not appear to be biased towards those who were dissatisfied, which might be expected if dissatisfied students were more likely to provide feedback. This may have been because respondents were incentivised to complete the SAES survey with a $£ 1$ Amazon gift card. It should be noted that it was clear that the survey was run by an independent organisation and the incentive was not provided by the student's institution or conditional on their reported satisfaction. It is therefore unlikely that the incentive would have affected the respondent's impression of their institution when providing feedback.

Table 1: Descriptive Statistics of Variables in the Sample

\begin{tabular}{|c|c|c|c|c|c|}
\hline Variables & Mean & Std. Dev. & Min & $\operatorname{Max}$ & Source \\
\hline Student Satisfaction Rating & 3.16 & 0.67 & 1 & 4 & SAES \\
\hline Satisfied & 0.88 & 0.32 & 0 & 1 & SAES \\
\hline University & $\mathrm{N} / \mathrm{A}$ & $\mathrm{N} / \mathrm{A}$ & 1 & 120 & SAES and UCU \\
\hline Subject & $\mathrm{N} / \mathrm{A}$ & $\mathrm{N} / \mathrm{A}$ & 1 & 17 & SAES and UCU \\
\hline Proportion of Casual Staff & 0.13 & 0.09 & 0.00 & 0.54 & $\mathrm{UCU}$ \\
\hline Proportion of Fixed Staff & 0.15 & 0.09 & 0.00 & 0.68 & $\mathrm{UCU}$ \\
\hline Proportion of Permanent Staff & 0.72 & 0.13 & 0.16 & 0.99 & $\mathrm{UCU}$ \\
\hline Number of Students ${ }^{a, b}$ & 9.92 & 0.46 & 6.87 & 11.79 & HESA \\
\hline Number of Students in Subject ${ }^{\mathrm{a}}$ & 7.33 & 0.62 & 1.61 & 9.99 & HESA \\
\hline Number of Academic Staff ${ }^{\mathrm{a}, \mathrm{b}}$ & 7.55 & 0.67 & 4.32 & 8.86 & HESA \\
\hline Number of Academic Staff in Subject ${ }^{\mathrm{a}}$ & 5.03 & 0.88 & 1.61 & 7.77 & HESA \\
\hline Russell Group & 0.44 & 0.50 & 0 & 1 & HESA \\
\hline London University & $\mathrm{N} / \mathrm{A}$ & $\mathrm{N} / \mathrm{A}$ & 0 & 1 & HESA \\
\hline
\end{tabular}

Note: All variables listed above have 8,767 observations except Number of Students in Subject $(8,666)$ and Number of Academic Staff in Subject $(8,572)$. UCU responses based on fewer than five responses in a universitysubject observation have been excluded. ${ }^{a}$ means natural logarithm of variable has been used. ${ }^{\mathrm{b}}$ refers to number at university-level (and not university-subject level). Source: Author's calculations from UCU, SAES and HESA data.

Around $2 \%$ of observations in the sample indicated that no undergraduate teaching was delivered by staff employed on a casual contract. It should be cautioned that the proportion used for this analysis comes from survey data and it may be the case that the information is inaccurate, particularly in larger departments where respondents may know less about the contractual arrangements of their colleagues. This reiterates the motivation for restricting the sample to observations which are based on the average of at least five responses. Furthermore, respondents were sourced from the UCU's mailing list, so this is not necessarily a representative sample of the university sector.

It might be expected that respondents would have been more likely to complete the UCU survey if they perceived the level of staff casualisation to be high. However, this doesn't seem to be witnessed in the data, with around $45 \%$ of observations reporting a proportion of teaching by casual staff lower than $10 \%$ and $80 \%$ of observations reporting a proportion lower than $20 \%$. The average reported proportion was $13 \%$, indicating that in a typical week $13 \%$ of undergraduate teaching was conducted by staff on a casual contract. There are, however, some university-subject observations which exhibit a much higher proportion of casual teaching: the highest observation in our dataset is $54 \%$.

Interestingly, and perhaps surprisingly, the average proportion of casual teaching is $12 \%$ 
Table 2: List of Subject Areas in the Sample

\begin{tabular}{ll}
\hline Subject Area & \% of Observations \\
\hline Architecture, building \& planning & $0.34 \%$ \\
Biological sciences & $13.12 \%$ \\
Business \& administrative studies & $8.69 \%$ \\
Combined & $1.46 \%$ \\
Creative arts \& design & $9.07 \%$ \\
Education & $3.13 \%$ \\
Engineering \& technology & $5.01 \%$ \\
Historical \& philosophical studies & $6.22 \%$ \\
Languages & $10.04 \%$ \\
Law & $2.11 \%$ \\
Mass communications \& documentation & $0.65 \%$ \\
Mathematical sciences \& computer science & $6.68 \%$ \\
Medicine \& dentistry & $3.18 \%$ \\
Physical sciences & $8.83 \%$ \\
Social studies & $11.68 \%$ \\
Subjects allied to medicine & $9.39 \%$ \\
Veterinary science \& agriculture \& related subjects & $0.41 \%$ \\
\hline
\end{tabular}

Note: Subject areas are provided at the JACS1 level. Source: Author's calculations based on UCU, SAES and HESA data.

for Russell Group members, compared to $15 \%$ for non-Russell Group institutions, suggesting that more research-focused universities are shifting a lesser proportion of teaching onto casual staff than other institutions. This may indicate that casualisation occurs as a result of financial concerns rather than outsourcing to permit permanent staff greater research time.

It can be seen that the majority of teaching in the sample is conducted by permanent staff; on average, $72 \%$ of teaching is conducted by staff on permanent contracts. The proportion of teaching by staff on fixed contracts is, on average, $15 \%$.

At the university-level, there are, on average, around 10 students for every academic member of staff. At the university-subject level, this figure is around 7 students for every academic member of staff.

Finally, of the 120 universities in the sample, 24 are Russell Group members, meaning that all Russell Group members are present in the sample. Additionally, there are 23 universities in the sample situated in the London region.

\section{$5 \quad$ Methodology}

As a result of the discrete and ordered nature of the dependent variable (student satisfaction), a multinomial discrete choice model is adopted, namely the ordered logit model. This model is built around a latent regression where $y^{*}$ is the unobserved dependent variable (true level of student satisfaction), $x$ is a vector of explanatory variables, $\beta$ an 
unknown parameter vector and $\epsilon$ an error term with a logistic distribution:

$$
y_{i}^{*}=\beta^{\prime} X_{i}+\epsilon_{i}
$$

The true level of student satisfaction $\left(y^{*}\right)$ is not observed but $y$, the student satisfaction rating given by the individual, is observed:

$$
\begin{aligned}
& y=1 \text { (student 'not at all satisfied') if } y^{*} \leq 1 \\
& y=2 \text { (student 'not very satisfied') if } 1<y^{*} \leq \mu_{1} \\
& y=3 \text { (student 'fairly satisfied') if } \mu_{1}<y^{*} \leq \mu_{2} \\
& y=4 \text { (student 'very satisfied') if } \mu_{2}<y^{*} \leq \mu_{3}
\end{aligned}
$$

With $\mu_{1}, \mu_{2}$ and $\mu_{3}$ being unknown threshold variables to be determined. Note that $\operatorname{Pr}\left(y_{i}=j\right)=\operatorname{Pr}\left(y_{i}\right.$ is in the jth range), where $J=1,2,3,4$. Therefore, the probability that $\mathrm{y}$ will take on a particular value is expressed as:

$$
\operatorname{Pr}\left(y_{i}=j \mid X\right)=F\left(\mu_{j}-\beta^{\prime} X_{i}\right)-F\left(\mu_{j-1}-\beta^{\prime} X_{i}\right)
$$

With $F($.$) representing the cumulative distribution function of the logistic distribution,$ such that $F(a)=1 /[1+\exp (a)]$. This implies that:

$$
\operatorname{Pr}\left(y_{i}=j \mid X\right)=\frac{1}{1+e^{-u_{j}+\beta^{\prime} X_{i}}}-\frac{1}{1+e^{-u_{j-1}+\beta^{\prime} X_{i}}}
$$

For this study, we begin by examining a latent regression of form (1), controlling for a number of observable characteristics such as Russell Group membership, student numbers and staff numbers (both at the university and the university-subject level).

However, it could be argued that these observable characteristics are insufficient to alleviate omitted variable concerns as unobserved characteristics such as financial wealth and management style remains unobserved. Thus, to overcome such a potential criticism, we also estimate a specification which controls for university. By controlling for university, we are eliminating any unobserved characteristics associated with a given university which might affect its student satisfaction rating or propensity to utilise casual teaching staff.

It could be further argued that this solution is still insufficient, as there may be characteristics at the subject level which are confounding our findings, resulting in endogeneity concerns. Obviously, we cannot control for both subject and university simultaneously as an interaction term, as this removes all variation. The usual method to deal with this problem is to utilise panel series data, so that university-subject fixed effects can be estimated. However, the UCU survey was only conducted for 2014-15 and no time-varying source of suitable information exists to adequately capture the proportion of casual teaching time. Consequently, we adopt the novel approach of grouping subjects together into 'faculties' within a given university, and controlling for characteristics at this level. We thereby eliminate any unobserved characteristics at the university-faculty level, which is likely to remove unobserved variables such as management quality and the financial wealth of a faculty. 
Thus, in latent regression (2), we control for university-faculty, along with student numbers at the university-subject level. We explain in more detail below how the faculty variable is constructed.

$$
\text { StudentSatisfaction }_{i, j, k}=\alpha+\beta \text { CasualStaff }_{j, k}+\gamma X_{j}+\phi U_{j, k}+\epsilon_{i, j, k}
$$

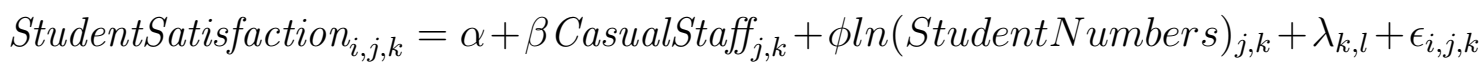

In both specifications, $i$ refers to the student, $j$ to the university, $k$ to the subject and $l$ to the faculty (group of subjects). $\beta$ is the coefficient of interest: a positive and significant value implies that the proportion of teaching by casual staff is associated with higher student satisfaction and vice versa for a negative coefficient.

In the first instance, $X_{j}$ is a vector of control variables at the university-level, including the $(\log )$ number of students at the institution, (log) number of academic staff at the institution, a dummy variable if the university is based in London and a dummy variable for Russell Group membership.

Unfortunately, HESA data is not disaggregated at the university-subject level for financial income and key indicator variables (such as surplus to expenditure ratio), so it is not possible to sufficiently control for these variables at this level. Given that financial health is likely to be correlated with both student satisfaction and levels of staff casualisation, there may be endogeneity concerns. To alleviate such concerns, controls for student numbers, staff numbers and total expenditure at the university-subject level are included, which should act, somewhat, as proxies for the financial health of a department.

To this end, $U_{j, k}$, a vector of control variables at the university-subject level is included, including proportion of teaching by staff on a fixed contract, number of students and number of academic staff.

However, it is arguably insufficient to control only for observable characteristics whilst omitting unobserved characteristics which may conceivably be correlated with both student satisfaction and the proportion of casual staff. This endogeneity problem is discussed in more detail in Section 6.

Therefore, we estimate specification (2), controlling for university, to remove universitylevel unobserved characteristics. Given the cross-sectional nature of our data, we cannot control simply for subject within university. This motivates us to group subjects together into 'faculties'. Hence, in addition to controlling for university, we separately control for university-faculty, to remove unobserved characteristics at the faculty level within university.

In determining these 'faculties', we wish to group together subjects that are likely to have similar management structures and sources of finance but, due to sample size issues, there is a trade-off between disaggregating faculties to a fine degree and ensuring that there remains a large enough sample size in each faculty grouping. We therefore proceed by splitting the sample into humanities and sciences faculties $(\mathrm{H} / \mathrm{S})$ and, separately, into humanities, business and other faculties, and sciences $(\mathrm{H}, \mathrm{B} \& \mathrm{O} / \mathrm{S}){ }^{4}$

\footnotetext{
${ }^{4}$ Faculty groups are denoted by letters $\mathrm{H}, \mathrm{S}$ and B\&O. H contains the humanities subjects of social studies, law,
} 
All specifications are estimated with robust standard errors to account for any potential heteroskedasticity or serial correlation. Additionally, the data is weighted using the weights provided in the SAES, to account for the fact that the survey sample design did not fully reflect the demographic split of the university population.

To summarise how we proceed, we estimate two sets of specifications, the first based on controlling for observable characteristics which provides interesting relationships between staff casualisation, student satisfaction and university characteristics but may suffer from endogeneity bias. This motivates the second specification which includes university controls and, moreover, university-faculty controls, holding constant a set of subjects within a university to control for unobserved characteristics such as faculty wealth and faculty management styles.

\section{Results and Discussion}

The estimated results from a variety of specifications controlling for observable characteristics are presented below. First, we estimate the most parsimonious model, before adding various controls to examine the effect of each additional variable (Table 3 ). Table 4 presents the associated marginal effects for the estimates of the ordered logistic models.

It can be seen that, for all specifications, there is a negative coefficient attached to the variable of interest (proportion of teaching by casual staff), indicating that, as the proportion increases, student satisfaction decreases. This is true even in the most parsimonious model, which has a negative and statistically significant coefficient. Generally, as more controls are added, the coefficient of interest decreases in absolute magnitude.

In specifications (2) to (4), various controls are included to alleviate omitted variable bias in observable characteristics. Column (2) includes controls for the proportion of teaching conducted by staff on fixed contracts, as well as dummy variables for being located in London and being a member of the Russell Group. Column (3) additionally includes the number of students and staff at each institution and (4) includes student and staff numbers at the university-subject level.

Institutions with a greater number of students are associated with lower student satisfaction, whilst having more staff is associated with higher student satisfaction. This echoes other empirical results found in the literature, which emphasise the importance of student-staff ratios on student satisfaction (Lenton 2015). These findings also hold at the university-subject level: more students in a given subject is associated with lower student satisfaction, whilst more subject staff members is correlated with higher student satisfaction.

Being a London-based university reduces student satisfaction in all specifications. This matches evidence discussed in the literature, with possible reasons being the high cost of living in London and the lack of campus-life both driving down student satisfaction (Bell \& Brooks 2018).

Russell Group membership is only found to significantly affect student satisfaction in

languages, mass communications \& documentation and historical \& philosophical studies. S contains the science subjects of biological sciences, medicine \& dentistry, physical sciences, subjects allied to medicine, veterinary sciences, mathematical sciences \& computer science and engineering \& technology. B\&O contains the subjects business \& administrative studies, architecture building \& planning, combined subjects, creative arts \& design and education. 
Table 3: Logistic Regression for Student Satisfaction - Characteristics Model - Estimation Results

\begin{tabular}{lllll}
\hline Variables & $(1)$ & $(2)$ & $(3)$ & $(4)$ \\
\hline Prop Casual & $-0.882^{* * *}$ & $-0.699^{* *}$ & $-0.799^{* * *}$ & $-0.602^{* *}$ \\
& $(0.270)$ & $(0.274)$ & $(0.275)$ & $(0.286)$ \\
Prop Fixed & & $0.880^{* * *}$ & $0.740^{* * *}$ & $0.591^{* *}$ \\
& & $(0.265)$ & $(0.266)$ & $(0.279)$ \\
Russell Group $=1$ & $0.144^{* * *}$ & 0.00310 & -0.0342 \\
& $(0.0481)$ & $(0.0727)$ & $(0.0750)$ \\
London =1 & $-0.283^{* * *}$ & $-0.373^{* * *}$ & $-0.371^{* * *}$ \\
& & $(0.0708)$ & $(0.0748)$ & $(0.0754)$ \\
Students (uni) & & $-0.385^{* * *}$ & $-0.281^{* * *}$ \\
& & & $(0.0876)$ & $(0.101)$ \\
Staff (uni) & & $0.296^{* * *}$ & $0.233^{* * *}$ \\
& & & $(0.0779)$ & $(0.0879)$ \\
Students & & & $-0.165^{* * *}$ \\
& & & & $(0.0610)$ \\
Staff & & & & $0.0945^{* *}$ \\
& & & & $(0.0395)$ \\
Observations & 8,767 & 8,767 & No & No \\
Uni Control & No & No & & \\
\hline
\end{tabular}

Note: All models are weighted using survey weights. Standard errors are robust. $* * * \mathrm{p}<0.01, * * \mathrm{p}<0.05, *$ $\mathrm{p}<0.1$. Source: Author's calculations based on UCU, SAES and HESA data.

Table 4: Logistic Regression for Student Satisfaction - Characteristics Model - Estimated Marginal Effects

\begin{tabular}{lllll}
\hline Student Satisfaction: & $(1)$ & $(2)$ & $(3)$ & $(4)$ \\
\hline Not at all satisfied & $0.0201^{* * *}$ & $0.0158^{* *}$ & $0.0180^{* * *}$ & $0.0136^{* *}$ \\
& $(0.00646)$ & $(0.00638)$ & $(0.00642)$ & $(0.00663)$ \\
Not very satisfied & $0.0752^{* * *}$ & $0.0594^{* *}$ & $0.0676^{* * *}$ & $0.0509^{* *}$ \\
& $(0.0232)$ & $(0.0234)$ & $(0.0234)$ & $(0.0243)$ \\
Fairly satisfied & $0.0835^{* * *}$ & $0.0662^{* *}$ & $0.0758^{* * *}$ & $0.0568^{* *}$ \\
& $(0.0254)$ & $(0.0259)$ & $(0.0260)$ & $(0.0269)$ \\
Very satisfied & $-0.179^{* * *}$ & $-0.141^{* *}$ & $-0.161^{* * *}$ & $-0.121^{* *}$ \\
& $(0.0546)$ & $(0.0553)$ & $(0.0555)$ & $(0.0575)$ \\
Observations & 8,767 & 8,767 & 8,767 & 8,572 \\
Uni Control & No & No & No & No \\
\hline
\end{tabular}

Note: Standard errors are robust. ${ }^{* * *} \mathrm{p}<0.01,{ }^{* *} \mathrm{p}<0.05,{ }^{*} \mathrm{p}<0.1$. Source: Author's calculations based on UCU, SAES and HESA data.

specification (2), which does not include variables for the number of staff and students. In this case, Russell Group members have a higher student satisfaction than non-members. This result is in contrast to Nurunnabi \& Abdelhadi (2019) but in line with Lenton (2015) and Bell \& Brooks (2018), albeit those authors study a different survey of student satisfaction, using the national student survey (NSS).

The fact that this variable is no longer significant with the inclusion of staff and stu- 
dent number variables suggests that the effect on student satisfaction of being a Russell Group university is well proxied by university size. Note that, whilst the coefficient on Russell Group membership is not significant in specifications (3) and (4), the results are insensitive to its inclusion.

Table 4 presents the marginal effects of all estimated specifications, allowing the effect to be quantified in terms of probabilities. Examination of the marginal effects (focusing on the preferred specification of column 4), reveals that a one percentage point increase in the proportion of teaching delivered by casualised staff is associated with a 0.12 percentage point decrease in the probability that a student will be 'very satisfied'. Instead, the probability that a student is 'fairly satisfied' increases by around $0.06 \mathrm{pp}$, 'not very satisfied' by $0.05 \mathrm{pp}$ and 'not at all satisfied' by around $0.01 \mathrm{pp}$. The positive marginal effect associated with 'fairly satisfied' does not indicate that increasing the proportion of teaching by casual staff will increase student satisfaction but instead that responses switch from 'very satisfied' to just 'fairly satisfied'.

As mentioned earlier, there may be concerns that, whilst these specifications control for a number of observable characteristics, unobservable variables are omitted. If such unobserved factors are correlated with both student satisfaction and the proportion of casual teaching, then the results would be biased. There are several unobservable variables which we might suppose are correlated with both the dependent and the independent variable, including financial characteristics, management and the level of casual teaching conducted by $\mathrm{PhD}$ students or early career academics.

Let us consider first the case of university-faculty management being the omitted variable - where it might be expected that good management increases student satisfaction and means that staff turnover is lower, reducing the need for a high proportion of casual staff. Then, we would expect that endogeneity bias would serve to inflate the true results, meaning that our findings would be an over-estimate of the true effect. Similarly, considering income and wealth at the department (university-subject) level, we might expect that wealthier departments would see higher student satisfaction, perhaps because they are able to use their wealth to spend lavishly on expensive equipment and impressive buildings, and lower proportions of casual teaching as there is less of a financial imperative to do so.

On the other hand, the unobserved confounder might be correlated with both student satisfaction and casual teaching proportion in the same direction, in which case the endogeneity bias would serve to attenuate our results, meaning the results presented in Table 3 are a lower bound of the true effect. One candidate variable which would exhibit these properties (i.e. is correlated with student satisfaction and staff casualisation in the same direction) is the propensity of $\mathrm{PhD}$ students to teach. It might be plausible to assume that students prefer being taught by $\mathrm{PhD}$ students and that $\mathrm{PhD}$ students are more likely to be employed on casual, rather than permanent, contracts. In a similar vein, as discussed above, regarding department income and wealth, it may be the case that richer departments (which have higher student satisfaction due to better facilities) can afford to fund more PhD students, who are then employed on casual contracts; or that wealthier departments attract prestigious guest lecturers employed on casual contracts. In all three cases, we would see endogeneity bias result in estimates that underestimate the true effect.

Without knowing what unobservable variables are driving our results (if any), it is not im- 
mediately clear, a priori, whether endogeneity bias will result in over- or under-estimated coefficients. This is therefore an empirical question, which can be somewhat resolved below.

To alleviate these endogeneity concerns, specifications are estimated controlling for university as well as faculty (groups of subjects). The estimated results are presented below in Table 5. The marginal effects associated with the estimates of these ordered logistic specifications are given in Table 6 .

Firstly, a university control by itself is included in the parsimonious specification (column 1). The coefficient is statistically significant and negative, with a larger coefficient (in absolute terms) relative to specifications controlling for university characteristics. This suggests that the omitted variable bias is attenuating the results in Table 3, suggesting that the omitted variable is correlated with student satisfaction and staff casualisation in the same direction. This does not necessarily mean that the aforementioned omitted variable is indeed propensity of $\mathrm{PhD}$ students to teach, as hypothesised for illustrative purposes above. We have no evidence as to what these omitted variables are and so cannot make a definitive conclusion, other than that the evidence suggests the omitted variable is correlated with the dependent and independent variable in the same direction.

In column 2, we additionally control for the number of students at the university-subject level. It can be seen that having more students at the university-subject level reduces student satisfaction to a similar, albeit slightly higher, degree as the proportion of casual teaching time. Given that we would expect financially constrained institutions to seek higher student numbers, it is interesting to note that this will have negative effects on student satisfaction but, importantly, that this could be offset by reducing the proportion of casual teaching time (where possible).

Secondly, we include university-faculty level controls to alleviate concerns that there might be unobservable differences between faculties within a university, such as in management styles, management quality, likelihood of $\mathrm{PhD}$ students teaching, the availability of guest lecturers and key financial variables. In (3), we control for university-faculty where we split subjects into either 'science' or 'humanity, business and other subjects'. In this instance, the effect of the proportion of casual teaching time is similar to that of the parsimonious model (column 1), although statistical significance is reduced (but remains statistically significant at the $5 \%$ confidence level). The reduction in statistical significance may reflect the reduction in degrees of freedom as we are comparing student satisfaction in each university between two subject groupings (faculties). Specification (4) includes the number of students at subject level which reduces the absolute magnitude of the coefficient of interest.

Finally, in (5) we repeat the university-faculty analysis but define faculty in a more disaggregated manner, grouping subjects into three categories of faculty: 'sciences', 'humanities' and 'business and other subjects'. This is our preferred specification, as it disaggregates the subjects into a relatively fine categorisation. We see that the effect of the proportion of casual teaching time on student satisfaction is statistically significant and has the highest magnitude, in absolute terms, across our specifications. ${ }^{5}$

Similarly, the effect of the number of students at the university-subject level is also statistically significant and negative, and stronger (in absolute terms) than the effect of

\footnotetext{
${ }^{5}$ Note that the results are insensitive to whether engineering is defined as a 'science' faculty or if it is included in 'business and other subjects'.
} 
proportion of casual teaching time. We do not attempt to define faculty to a finer degree (i.e. categorising only two or three subjects into a faculty) as this would result in too few degrees of freedom for a robust analysis.

Table 5: Logistic Regression for Student Satisfaction - University and Faculty Controls Estimation Results

\begin{tabular}{llllll}
\hline Variables & $(1)$ & $(2)$ & $(3)$ & $(4)$ & $(5)$ \\
\hline Prop Casual & $-1.077^{* * *}$ & $-1.034^{* * *}$ & $-1.068^{* *}$ & $-0.899^{* *}$ & $-1.170^{* *}$ \\
& $(0.322)$ & $(0.323)$ & $(0.437)$ & $(0.444)$ & $(0.488)$ \\
Students & & $-0.124^{* *}$ & & $-0.122^{* *}$ & $-0.184^{* *}$ \\
& & $(0.0549)$ & & $(0.0616)$ & $(0.0721)$ \\
Observations & 8,767 & 8,666 & 8,767 & 8,666 & 8,666 \\
Uni Control & Yes & Yes & Yes & Yes & Yes \\
Faculty Effects & No & No & $\mathrm{H}, \mathrm{B} \& \mathrm{O} / \mathrm{S}$ & $\mathrm{H}, \mathrm{B} \& \mathrm{O} / \mathrm{S}$ & $\mathrm{H} / \mathrm{S} / \mathrm{B} \& \mathrm{O}$ \\
\hline \hline
\end{tabular}

Note: All models are weighted using survey weights. Faculty groups are denoted by letters H, S and B\&O. H contains the humanities subjects of social studies, law, languages, mass communications \& documentation and historical \& philosophical studies. S contains the science subjects of biological sciences, medicine \& dentistry, physical sciences, subjects allied to medicine, veterinary sciences, mathematical sciences \& computer science and engineering \& technology. B\&O contains the subjects business \& administrative studies, architecture building \& planning, combined subjects, creative arts \& design and education. Standard errors are robust. ${ }^{* * *} \mathrm{p}<0.01,{ }^{* *}$ $\mathrm{p}<0.05, * \mathrm{p}<0.1$. Source: Author's calculations based on UCU and SAES data.

Table 6: Logistic Regression for Student Satisfaction - University and Faculty Controls Estimated Marginal Effects

\begin{tabular}{llllll}
\hline Student Satisfaction: & $(1)$ & $(2)$ & $(3)$ & $(4)$ & $(5)$ \\
\hline Not at all satisfied & $0.0231^{* * *}$ & $0.0221^{* * *}$ & $0.0224^{* *}$ & $0.0188^{* *}$ & $0.0232^{* *}$ \\
& $(0.00720)$ & $(0.00718)$ & $(0.00932)$ & $(0.00941)$ & $(0.00980)$ \\
Not very satisfied & $0.0893^{* * *}$ & $0.0856^{* * *}$ & $0.0875^{* *}$ & $0.0735^{* *}$ & $0.0939^{* *}$ \\
& $(0.0268)$ & $(0.0268)$ & $(0.0358)$ & $(0.0363)$ & $(0.0392)$ \\
Fairly satisfied & $0.103^{* * *}$ & $0.0991^{* * *}$ & $0.103^{* *}$ & $0.0868^{* *}$ & $0.115^{* *}$ \\
& $(0.0310)$ & $(0.0311)$ & $(0.0424)$ & $(0.0430)$ & $(0.0484)$ \\
Very satisfied & $-0.216^{* * *}$ & $-0.207^{* * *}$ & $-0.213^{* *}$ & $-0.179^{* *}$ & $-0.232^{* *}$ \\
& $(0.0644)$ & $(0.0645)$ & $(0.0870)$ & $(0.0884)$ & $(0.0969)$ \\
Observations & 8,767 & 8,666 & 8,767 & 8,666 & 8,666 \\
Uni Control & Yes & Yes & Yes & Yes & Yes \\
Faculty Effects & No & No & H,B\&O/S & H,B\&O/S & H/S/B\&O \\
\hline \hline
\end{tabular}

Note: Faculty groups are denoted by letters H, S and B\&O. H contains the humanities subjects of social studies, law, languages, mass communications \& documentation and historical \& philosophical studies. S contains the science subjects of biological sciences, medicine \& dentistry, physical sciences, subjects allied to medicine, veterinary sciences, mathematical sciences \& computer science and engineering \& technology. B\&O contains the subjects business \& administrative studies, architecture building \& planning, combined subjects, creative arts \& design and education. Standard errors are robust. ${ }^{* * *} \mathrm{p}<0.01,{ }^{* *} \mathrm{p}<0.05,{ }^{*} \mathrm{p}<0.1$. Source: Author's calculations based on UCU and SAES data.

Table 6 presents the marginal effects of all estimated specifications. Examination of the marginal effects reveals that a one percentage point increase in the proportion of teaching delivered by casualised staff is associated with a 0.23 percentage point decrease in the probability that a student will be 'very satisfied'. Instead, the probability that a student is 'fairly satisfied' increases by around $0.12 \mathrm{pp}$, 'not very satisfied' by $0.09 \mathrm{pp}$ and 'not at 
all satisfied' by around 0.02pp.

To check the robustness of our results, the above specifications are re-estimated on a dataset where each university-subject observation is restricted to only three staff responses in the UCU dataset (and not five). The results are qualitatively similar, although the magnitude of coefficients are reduced by around $0.3 \mathrm{pp}$. The coefficient of interest, in our preferred specification (5), remains statistically significant but stands at -0.8033 compared to -1.170 . The change in coefficient likely reflects the unreliability of reported staff casualisation based on only three responses, where individuals might report lower casual proportions as they are less aware of colleagues' contracts. ${ }^{6}$

There are a number of potential mechanisms which could explain the finding that a higher proportion of casual teaching leads to lower student satisfaction. These mechanisms can be divided into reasons stemming from the nature of casual contracts and reasons stemming from the nature of individuals likely to accept casual contracts.

Firstly, students, most of whom pay $£ 9,000$ per year in tuition fees, may expect to be taught by qualified faculty members, employed on 'fair' contracts. Whilst such students might report being less satisfied if this were not the case, given the fact that students are unlikely to be be aware of the contractual arrangements of teaching staff, it is difficult to make a convincing argument here.

Secondly, casual teaching staff, often remunerated only for the duration of the lesson, may have less time to dedicate to preparing class materials or marking students' work (Klopper \& Power 2014). They may also have less out-of-class contact time available for students. All of these factors are likely to reduce student satisfaction (Richardson \& Radloff 2014).

Thirdly, casual staff may have less influence and be less able to determine the subject material and curriculum and may be restricted in the method of teaching demanded by their employer. This lack of influence on the form and method of teaching could lead to poor teaching outcomes, thereby affecting student satisfaction.

These mechanisms are related to the nature of the casual contract. The final mechanism we discuss relates to the type of individuals who may be more likely to be employed on casual rather than permanent contracts. Such individuals may have less teaching experience and receive less training, thereby resulting in lower teaching quality and hence lower student satisfaction (Percy \& Beaumont 2008). Existing research finds that parttime staff are less likely than full-time staff to experiment with their teaching or to teach potentially challenging material (AAUP 2016). As a related point, casual staff may be $\mathrm{PhD}$ students, who are just beginning their academic career and thus have less teaching experience. Students might also prefer to be taught by experienced or prestigious academics in order to feel that they are getting value for money.

Whilst these are just a few possible mechanisms to explain the results, the evidence is unable to pinpoint exactly which mechanism (or combination of mechanisms) is driving the finding. Further research may seek to investigate the driving mechanism.

As alluded to above, it is not clear whether student satisfaction is lower as a result of the type of individuals who are likely to accept casual contracts, or by the very nature of the contracts themselves. The data presented here is unable to distinguish between

\footnotetext{
${ }^{6}$ Full results are available on request.
} 
these two competing hypotheses as individual characteristics of casual staff were not asked in the UCU survey. It is therefore not possible to compare the age, or years of experience between casual and permanent/fixed staff. Furthermore, HESA does not provide information on individual characteristics, so it is not possible to use this source to shed light on the issue (notwithstanding the data issues of HESA atypical staff data). However, there is some evidence to suggest that a large proportion of causal staff are indeed PhD students. ${ }^{7}$

Whilst this distinction is unimportant for the principal conclusion, it does affect the prescription of policy. If casual staff do not differ from permanent staff in individual characteristics, then this suggests that casual contracts themselves are the issue, and HEIs should replace casual contracts with permanent or fixed equivalents. Conversely, if individual characteristics are different for casual and permanent staff, then the policy prescription would be to ensure that hiring is done comparably and not loaded onto less expensive, but less experienced, individuals.

For instance, it could be the case that PhD students, who are younger and less experienced than permanent professors, are providing a significant proportion of teaching whilst being employed on casual contracts. This would suggest that policymakers should not shift teaching load onto such individuals as a means of cutting costs, without expecting to see a reduction in student satisfaction.

Overall, the evidence suggests that increasing the proportion of teaching by casual staff is linked with a reduction in student satisfaction of their university experience. Whilst these results might seem small at the outset, the findings suggests that a five percentage point increase in the proportion of teaching delivered by staff employed on a casual contract leads to more than a one percentage point reduction in the probability that a student will be very satisfied with the university experience. It is important to remember how clustered student satisfaction scores are in national rankings and the importance of such scores in third-party rankings (Gibbons et al. 2015). As a result, policymakers have an incentive to consider employment practices in order to preserve student satisfaction and thus their position in university ranking tables (Chevalier \& Jia 2016).

The policy recommendation which follows from these results is that HEIs should be cautious of shifting teaching to academic staff on casual contracts, as this is likely to lead to lower student satisfaction.

\section{Conclusion}

Existing literature on the casualisation of teaching staff has focused on the effect of casual contracts on staff well-being and not the direct effect on students. Furthermore, the research methods in the existing literature tend to focus on case studies, perhaps stemming from a lack of suitable data with which to explore such relationships. On the other hand, there is a well established literature focusing on the determinants of student satisfaction but it predominantly investigates the NSS and has not studied the effect of casualisation on student satisfaction. In this paper, two proprietary datasets are utilised to examine the direct effect of teaching by casual staff on student satisfaction. An increase

\footnotetext{
${ }^{7}$ See UCU (2019) and Lopes \& Dewan (2014). This hypothesis would also be consistent with the suspected direction of omitted variable bias
} 
in the proportion of teaching by casual staff is found to reduce the probability of a student being very satisfied with the university experience.

More specifically, a one percentage point increase in the proportion of teaching by casual staff leads to a 0.23 percentage point reduction in the probability that the individual will be very satisfied with their time at university.

Given the increasing marketisation of higher education in the UK, and the need to attract students for the financial viability of universities, maintaining high student satisfaction is of great importance for university policymakers. The findings of this paper would suggest that policymakers should exercise caution when considering employing teaching staff on casual contracts, as this may lead to lower student satisfaction. Existing evidence suggests that university rankings, of which student satisfaction is one component, play an important role in helping students decide which university to attend, particularly for international students (Chevalier \& Jia 2016). Therefore, low student satisfaction could have negative effects on future demand.

Recent findings show that, in $2015 / 16$, around 25 to $30 \%$ of teaching was conducted by casual staff (UCU 2018), suggesting an upward trend in the use of casual contracts over time. $^{8}$ If the findings in this paper persist over time, then this would suggest universities which load an increasing proportion of teaching onto casual staff will observe a decrease in student satisfaction, potentially affecting their position in university ranking tables.

Further work may pursue a panel structure, which would require consistent data in multiple years, particularly for data on the proportion of teaching conducted by casual staff. This would benefit the literature both by eliminating endogeneity concerns and permitting an investigation into how the relationship between student satisfaction and staff casualisation has evolved over time. Moreover, improved data relating to the proportion of casual teaching ought to be collected without resorting to subjective survey methods. Such data-gathering could also collect information relating to the characteristics of individuals on casual contracts, to examine whether our finding is a result of the nature of the contract or the individuals. Exploring the key mechanisms behind the empirical finding would help refine policy conclusions.

\section{Acknowledgements}

The author would like to thank Matt Waddup at the University and College Union and Nick Hillman from the Higher Education Policy Institute for providing access to the data. The author is also grateful to Gavan Conlon and Maike Halterbeck for providing the idea and all their help and guidance throughout, and also to Alice Battison, Colin Green, Rohit Ladher, Edgar Liberis and Deborah Williams for helpful comments and suggestions.

\footnotetext{
${ }^{8}$ Note however that the figures are not directly comparable. The estimate from $2015 / 16$ is derived based on institution responses to freedom of information requests. As such, the sample differs to the sample used in this study.
} 


\section{References}

AAUP. 2016. "Higher Education at a Crossroads: The economic value of tenure and the security of the profession 2016." Academe, 9-22.

Afonso, Alexandre. 2014. "How Academia Resembles a Drug Gang." SSRN Working Paper.

Allmer, Thomas. 2018. "Always-On and Flexible: A Case Study of Academics as Information Workers." European Journal of Communication, 33(4): 381-395.

Bell, Adrian R., and Chris Brooks. 2018. "What makes students satisfied? A discussion and analysis of the UK's national student survey." Journal of Further and Higher Education, 42(8): 1118-1142.

Broecke, Stijn. 2015. "University rankings: do they matter in the UK?" Education Economics, 23(2): $137-161$.

Chevalier, Arnaud, and Xiaoxuan Jia. 2016. "Subject-Specific League Tables and Students' Application Decisions." Manchester School, 84(5): 600-620.

Figlio, David N., Morton O. Schapiro, and Kevin B. Soter. 2015. "Are Tenure Track Professors Better Teachers?" The Review of Economics and Statistics, 97(4): 715-724.

Gibbons, Stephen, Eric Neumayer, and Richard Perkins. 2015. "Student satisfaction, league tables and university applications: Evidence from Britain." Economics of Education Review, 48: 148 - 164.

Gill, Rosalind. 2014. "Academics, Cultural Workers and Critical Labour Studies." Journal of Cultural Economy, $7(1): 12-30$.

Horstschräer, Julia. 2012. "University rankings in action? The importance of rankings and an excellence competition for university choice of high-ability students." Economics of Education Review, 31(6): 1162-1176.

Junor, Anne. 2004. "Casual University Work: Choice, Risk, Inequity and the Case for Regulation." The Economic and Labour Relations Review, 14(2): 276-304.

Klopper, Christopher, and Bianca Power. 2014. "The Casual Approach to Teacher Education: What Effect Does Casualisation Have for Australian University Teaching." The Australian Journal of Teacher Education, 39(4).

Lenton, Pamela. 2015. "Determining student satisfaction: An economic analysis of the National Student Survey." Economics of Education Review, 47: 118 - 127.

Lopes, Ana, and Indra Dewan. 2014. "Precarious pedagogies? The impact of casual and zero-hour contracts in Higher Education." Journal of Feminist Scholarship, 7(8).

Loveday, Vik. 2018. "The neurotic academic: anxiety, casualisation, and governance in the neoliberalising university." Journal of Cultural Economy, 11(2): 154-166.

Nurunnabi, Mohammad, and Abdelhakim Abdelhadi. 2019. "Student satisfaction in the Russell Group and Non-Russell Group Universities in UK." Data in Brief, 22: 76 - 82.

Percy, Alisa, and Rosemary Beaumont. 2008. "The casualisation of teaching and the subject at risk." Studies in Continuing Education, 30(2): 145-157.

Richardson, Sarah, and Ali Radloff. 2014. "Allies in learning: critical insights into the importance of staff-student interactions in university education." Teaching in Higher Education, 19(6): 603-615.

SAES, HEPI, and HEA. 2015. "Student Academic Experience Survey 2013-14." https://www. hepi. ac. uk/ wp-content/uploads/2014/05/HEA_HEPI-Report_WEB_ 160514. pdf.

Soo, Kwok Tong, and Caroline Elliott. 2010. "Does price matter? Overseas students in UK higher education." Economics of Education Review, 29(4): 553-565.

UCU. 2018. "Precarious education: how much university teaching is being delivered by hourly-paid academics?" https://www. ucu. org. uk/media/9258/ Precarious-education-how-much-university-teaching-is-being-delivered-by-hourly-paid-academics-Feb-18/ pdf/HP_ uni_teaching_March_2018. pdf.

UCU. 2019. "Counting the Costs of Casualisation in Higher Education." https://www. ucu. org. uk/ media/10336/Counting-the-costs-of-casualisation-in-higher-education-Jun-19/pdf/ucu_ casualisation_in_HE_ survey_ report_Jun19. pdf. 


\section{Annex}

\section{List of Universities}

\begin{tabular}{|c|c|}
\hline Aberystwyth University & Royal Central School of Speech and Drama \\
\hline Anglia Ruskin University & Royal Holloway and Bedford New College \\
\hline Arts University Bournemouth & School of Oriental and African Studies \\
\hline Aston University & Sheffield Hallam University \\
\hline Bangor University & Southampton Solent University \\
\hline Bath Spa University & Staffordshire University \\
\hline Birkbeck College & Swansea University \\
\hline Birmingham City Unive & Teesside University \\
\hline Bournemouth University & Trinity Laban Conservatoire of Music and Danc \\
\hline Bournemoutn universily & University College Birmingham \\
\hline Brunel University London & University College London \\
\hline Canterbury Christ Church University & University for the Creative Arts \\
\hline Cardiff University & University of Aberdeen \\
\hline City University & University of Abertay Dundee \\
\hline Coventry University & University of Bath \\
\hline De Montfort University & University of Bedfordshire \\
\hline Edge Hill University & University of Birmingham \\
\hline Falmouth University & University of Bolton \\
\hline Glasgow Caledonian University & University of Bradford \\
\hline Glasgow School of Art & University of Brighton \\
\hline Goldsmiths College & University of Bristol \\
\hline Harper Adams University & University of Cambridge \\
\hline Heriot-Watt University & University of Central Lancashire \\
\hline Imperial College of Science, Technology and & University of Chester \\
\hline Medicine & University of Cumbria \\
\hline King's College London & University of Derby \\
\hline Kingston University & University of Dundee \\
\hline Leeds Beckett University & University of Durham \\
\hline Liverpool Hope University & University of East Anglia \\
\hline Liverpool John Moores University & University of East London \\
\hline London Metropolitan University & University of Edinburgh \\
\hline London School of Economics & University of Essex \\
\hline London South Bank University & University of Exeter \\
\hline Loughborough University & University of Glasgow \\
\hline Lougnioorougn Universily & University of Gloucestershire \\
\hline Manchester Metropolitan Universit. & University of Greenwich \\
\hline Middlesex University & University of Hertfordshire \\
\hline Newman University & University of Huddersfield \\
\hline Nottingham Trent University & University of Hull \\
\hline Open University & University of Keele \\
\hline Oxford Brookes University & University of Kent \\
\hline Queen Margaret University, Edinburgh & University of Lancaster \\
\hline Queen Mary University of London & University of Leeds \\
\hline Queen's University of Belfast & University of Leicester \\
\hline Robert Gordon University & University of Lincoln \\
\hline Roehampton University & University of Liverpool \\
\hline
\end{tabular}


University of Manchester

University of Newcastle-upon-Tyne

University of Northampton

University of Northumbria at Newcastle

University of Nottingham

University of Oxford

University of Plymouth

University of Portsmouth

University of Reading

University of Salford

University of Sheffield

University of South Wales

University of Southampton

University of St Andrews

University of St Mark and St John

University of Stirling
University of Strathclyde

University of Sunderland

University of Surrey

University of Sussex

University of the Arts, London

University of the West of England, Bristol

University of Ulster

University of Wales Trinity Saint David

University of Warwick

University of Westminster

University of Winchester

University of Wolverhampton

University of Worcester

University of York

York St John University 